\title{
Measurement and characterization of engineered titanium dioxide nanoparticles in the environment"
}

\author{
Zhuan-xi LUO ${ }^{\dagger+1}$, Zhen-hong WANG ${ }^{1}$, Bin XU ${ }^{1}$, Ionnis L. SARAKIOTIS ${ }^{2}$, \\ Gijs DU LAING ${ }^{2}$, Chang-zhou YAN ${ }^{\dagger 1}$ \\ $\left({ }^{1}\right.$ Key Laboratory of Urban Environment and Health, Institute of Urban Environment, Chinese Academy of Sciences, Xiamen 361021, China) \\ ('Laboratory of Analytical Chemistry and Applied Ecochemistry, Ghent University, Ghent 9000, Belgium) \\ †E-mail: zxluoire@163.com; czyan@iue.ac.cn \\ Received Apr. 29, 2014; Revision accepted July 21, 2014; Crosschecked July 21, 2014
}

\begin{abstract}
Titanium dioxide nanoparticles $\left(\mathrm{TiO}_{2}-\mathrm{NPs}\right)$ are common components used in sunscreens, cosmetics, industrial applications, and many other products. Concerning their high production and widespread applications, characterization and quantification of $\mathrm{TiO}_{2}-\mathrm{NPs}$ in various matrixes is a topic of great interest for researchers studying their potential environmental and health impacts. Validated and easily applicable analytical tools are required to develop and implement regulatory frameworks and an appropriate risk assessment for engineered nanoparticles (ENPs). Herein, we provide a critical review of the current knowledge available on world-wide production and measured environmental concentrations as well as on available techniques to measure and characterize these ENPs in the environment.
\end{abstract}

Key words: Titanium dioxide $\left(\mathrm{TiO}_{2}\right)$, Engineered nanoparticles (ENPs), Environmental concentration, Production, Analytical method

doi: 10.1631 jzus.A1400111

Document code: A

CLC number: X830.2

\section{Introduction}

Nanotechnology is expected to become one of the pillars of the next industrial revolution (Zänker and Schierz, 2012; Gao et al., 2013). A large variety of engineered nanoparticles (ENPs) will be encountered much more frequently due to a tremendous growth in their applications in various products. These applications include cosmetics and skin-care products, sporting facilities, paints, textiles, water purification and soil remediation materials, electronics, and many others. Yet a life cycle assessment of most nanoparticles (NPs) is still under consideration.

\footnotetext{
${ }^{\ddagger}$ Corresponding authors

* Project supported by the National Natural Science Foundation of China (Nos. 41271484 and 41261079), and the Fujian Provincial Natural Science Foundation of China (Nos. 2013J01166 and 2012J05030) (C) Zhejiang University and Springer-Verlag Berlin Heidelberg 2014
}

The exposure of the public (e.g., workers and consumers) as well as their release into the environment is expected, as some NPs have already demonstrated their capabilities to cause harmful effects on humans and the environment (Farré et al., 2009; Kiser et al., 2012; Lin et al., 2012; Gottschalk et al., 2013; Shi et al., 2013). Therefore, understanding the safety, environmental impacts, and human health implications of nanotechnology-based products is of paramount importance. An appropriate risk assessment is needed, which, to some extent, requires the availability of proper analytical methods (Maynard et al., 2006). Until now, the measurement, characterization, and quantification of ENPs are still challenging tasks, restricting our understanding of the environmental and human health risks arising from the use of nanotechnology and related products. The properties of ENPs can differ strongly between each other and from their (chemically identical) bulk materials, and may 
vary over time or be dependent on the surrounding matrixes. Therefore, validation of analytical methods appropriate for ENPs is challenging, particularly in different matrixes, and multi-method approaches are often required to provide reliable data as well as to assess and control the limitations of different techniques. This demands that there is not only a comprehensive number of cross-scientific studies but also availability of validated and easily applicable analytical methods (Fabricius et al., 2014).

Titanium dioxide NPs $\left(\mathrm{TiO}_{2}-\mathrm{NPs}\right)$ have raised considerable attention due to their rapidly increasing production and applications as well as their potential release into the environment (Robichaud et al., 2009; Gao et al., 2013). In addition, NPs are being transported to receiving waters with increasing frequency (Luo et al., 2011). Direct evidence of the release of synthetic NPs from urban exterior facade paints into the aquatic environment has been documented (Kaegi et al., 2008). Generally, $\mathrm{TiO}_{2}$-NPs are synthesized for their anatase, rutile, or brookite structure. Each of these crystalline structures has unique properties (Macwan et al., 2011). The most common procedure for synthesis of $\mathrm{TiO}_{2}$-NPs utilizes the hydrolysis of titanium (Ti) salts in an acidic solution (Mahshid et al. 2007). To increase photostability and prevent aggregation, $\mathrm{TiO}_{2}$ nanomaterials (e.g., particles, tubes, and wires) are commonly coated with aluminum, silicon, or polymers (Carlotti et al., 2009). The produced $\mathrm{TiO}_{2}$-NPs are widely used for applications, such as pigments, coatings, sunscreen, and cosmetic additives, and increasingly for the photocatalytic degradation of various pollutants in water, air, and soil. The wide application of $\mathrm{TiO}_{2}-\mathrm{NPs}$ benefits from their stronger catalytic activity when compared to its bulk material. The increase in catalytic activity has been attributed to a smaller size, which results in a larger surface area per unit mass. However, these unique properties could potentially also lead to unexpected environmental hazards with possible serious effects on human health. Since 2001, most industrially developed economies have started investing into research to develop an integrated management framework for these emerging pollutants. Most previous studies on the health risk and environmental impacts of $\mathrm{TiO}_{2}$-NPs have focused on their biological effects and toxicities. Generation of reactive oxygen species (ROS) and their inflammatory effects are considered as the main mechanisms for $\mathrm{TiO}_{2}$-NPs toxicity. Toxicity studies mainly report a risk from $\mathrm{TiO}_{2}$-NPs due to inhalation (inflammation and possible link to asthma). Moreover, titania has also been linked to Crohn's disease through gastrointestinal intake and it has been classified as a possibly carcinogen (Lomer $e t$ al., 2002; Fadeel and Garcia- Bennett, 2010; Hussain et al., 2011; Weir et al., 2012). In the environment, less is known about how $\mathrm{TiO}_{2}$-NPs affect organisms, although it has been shown to inhibit growth of algae and plants, and bioaccumulate in Daphnia magna. Very recently, toxicities of $\mathrm{TiO}_{2}$-NPs to benthic organisms were also reported (Ma et al., 2010; Du et al., 2011; Weir et al., 2012; Li et al., 2014a; 2014b). It should be mentioned that up till now, all studies are restricted to simulated environmental conditions in a laboratory. In situ investigations of nanomaterials in the environment are still an emerging research field. Due to the natural presence of $\mathrm{TiO}_{2}$-NPs in the environment, one might consider that particle size is the primary toxicity factor. Despite this, recent studies have shown that particle size is only a single (and perhaps minor) factor influencing the toxicity of NPs (Weir et al., 2012). The risk assessment of $\mathrm{TiO}_{2}$-NPs is still a quite difficult task. Analytical methods for ENPs lack validation, thus the physicochemical characteristics of the tested NPs can hardly be demonstrated with enough reliable information to obtain valid conclusions (Menard et al., 2011; Zänker and Schierz, 2012).

Notably, it has been proposed that $\mathrm{TiO}_{2}$-NPs could serve as a sentinel, or tracer, for other nanomaterials, especially those of similar size and aggregation behavior due to their long-term use in commercial products (Kiser et al., 2009; Luo et al., 2011). By measuring and characterizing $\mathrm{TiO}_{2}$-NPs in the environment, we can facilitate understanding the potential transporting and fates of widely used engineered nanomaterials. In this review, we cover the production, possible concentration in different matrixes, and common or potential methods for characterization and measurement of engineered $\mathrm{TiO}_{2}$-NPs in the environment, aimed at enhancing our knowledge on how to measure and characterize engineered $\mathrm{TiO}_{2}$-NPs.

\section{Occurrence of engineered $\mathrm{TiO}_{2}-\mathrm{NPs}$}

\section{$2.1 \mathrm{TiO}_{2}$ production}

The global production of $\mathrm{TiO}_{2}$ already reached 5.70 million tons in 2008 with a growth rate of $4.3 \%$ 
(Chen, 2010). Its production is the highest production among all nanomaterials (Windler et al., 2012). In China, the production increased from 0.43 million tons in 2001 to 1.28 million tons in 2007, which made China the second largest producer after USA. Nowadays, the global production of $\mathrm{TiO}_{2}$ is predicted to be near 10 million tons, and it is expected to continue to increase until at least 2025 with greater reliance being placed upon nanosized $\mathrm{TiO}_{2}$ (Landsiedel et al., 2010). Nearly $70 \%$ of all $\mathrm{TiO}_{2}$ produced is used as a pigment in paints, but it is also used as a pigment in glazes, enamels, plastics, paper, fibers, foods, pharmaceuticals, cosmetics, and toothpastes (Weir et al., 2012). The production quantities of $\mathrm{TiO}_{2}$-NPs in China and in the rest of the world are shown in Table 1. Large variations in production are observed between different countries/regions, which can also be partly attributed to the different methods which are used to assess the production quantities, some of which have a limited accuracy. For $\mathrm{TiO}_{2}$-NPs in Europe, production ranges between 11-1000 tons were reported (Piccinno et al., 2012). However, some experts estimated the annual European $\mathrm{TiO}_{2}$-NPs production to be above 10000 tons. Generally, $\mathrm{TiO}_{2}$-NPs are manufactured worldwide in large quantities for use in a wide range of applications.

Table 1 Production quantities of $\mathrm{TiO}_{2}$-NPs in China and the rest of the world

\begin{tabular}{lcc}
\hline \multicolumn{1}{c}{ Country/region } & $\begin{array}{c}\text { Production } \\
\text { (ton/year) }\end{array}$ & Reference \\
\hline China & 1300 & Gao et al., 2013 \\
Europe median & 550 & Piccinno et al., 2012 \\
$\quad(25 / 75$ percentile) & $(55-3000)$ & \\
USA range & $7800-38000$ & Hendren et al., 2011 \\
Switzerland & 435 & Schmid and Riediker, \\
& & 2008 \\
Worldwide median & 3000 & Piccinno et al., 2012 \\
$\quad(25 / 75$ percentile $)$ & $(550-5500)$ & \\
\hline
\end{tabular}

\section{$2.2 \quad$ Measured environmental $\mathrm{TiO}_{2}-\mathrm{NPs}$ concentrations}

Measured environmental $\mathrm{TiO}_{2}$-NPs concentrations have been reported for the workplace, surface water, wastewater treatment plants (WWTPs) effluents, biosolids, and sediments (Table 2) (Luo et al., 2011; Gottschalk et al., 2013). In this context, a workplace is defined as a particular environment in which workers are exposed to NPs with the high likelihood of adverse health effects. Concentrations of atmospheric $\mathrm{TiO}_{2}$-NPs emitted from nanomaterial production processes have been measured using direct-reading methods like a condensation particle counter (CPC), scanning mobility particle sizer (SMPS), and diffusion charger (DC) in some particular workplaces. The CPC is a powerful tool to quantify really small NPs concentrations in a workplace. The SMPS is widely used for investigating particle-size distribution, and it comprises an electrostatic device with a differential mobility analyzer (DMA) for size distribution and a CPC for particles counting. The DC is an instrument for monitoring surface areas in real time, responding to particles smaller than $100 \mathrm{~nm}$ (Duarte et al., 2014). Lee et al. (2011) used a SMPS and a CPC to assess the exposure at workplaces manufacturing nanosized $\mathrm{TiO}_{2}$. A particle-number concentration for $\mathrm{TiO}_{2}$ of 11418 45889 particles $/ \mathrm{cm}^{3}$ was detected with a size distribution of 15-710.5 nm during the growth reaction. In contrast, the particle-number concentration of $\mathrm{TiO}_{2}$ ranged from 9512 to 16337 particles $/ \mathrm{cm}^{3}$ in European construction industries, where a self-cleaning coating (that contained $\mathrm{TiO}_{2}$ as an active nano-component) was sprayed on windows (van Broekhuizen et al., 2011). Also, an Aerasense NP monitor (NanoTracer), a portable aerosol sampler of Philips Aerasense (Eindhoven, the Netherlands) was used to measure particle concentrations at various workplaces. This NanoTracer provides real-time information about the number concentration (particles $/ \mathrm{cm}^{3}$ ), numberaveraged particle diameter, and surface area. It detects the concentration of NPs $\left(\mathrm{NPs} / \mathrm{cm}^{3}\right)$ within a range of 10-300 nm, simultaneously with the mean particles diameter over a time interval of $16 \mathrm{~s}$ or, in the fast mode, only the number of NPs per $\mathrm{cm}^{3}$ over a time interval of $3 \mathrm{~s}$ (Marra et al., 2010). van Broekhuizen et al. (2012) observed $\mathrm{TiO}_{2}$-NPs concentrations within a range of $0.005-0.021 \mathrm{mg} / \mathrm{m}^{3}$ in different manufacturing workplaces using the NanoTracer.

The release of engineered $\mathrm{TiO}_{2}$-NPs into the environment has been demonstrated to some extent via the measurement and characterization of $\mathrm{TiO}_{2}-$ NPs in surface water, wastewater treatment plant effluents, biosolids, and sediments (Table 2). A $\mathrm{TiO}_{2}$ concentration (almost completely colloidal or 
nanoparticulate) of surface water from UK averaged $2.1 \mu \mathrm{g} / \mathrm{L}$ in a range of $0.55-6.48 \mu \mathrm{g} / \mathrm{L}$ measured by subsequent filtration, cross-flow ultrafiltration, and inductively coupled plasma mass spectrometry (ICP-MS) (Neal et al., 2011). In wastewater treatment plants in Arizona, Colorado, California, Maryland, Iowa, and New York (USA), the $\mathrm{TiO}_{2}$ concentration ranged $<5.0-15.0 \mu \mathrm{g} / \mathrm{L}$ in the effluents and 1.8 $6.4 \mathrm{~g} / \mathrm{kg}$ in the biosolids, measured using a combination of filtration, acid digestion, ICP-MS, inductively coupled plasma optical emission spectroscopy (ICP-OES), and a scanning electron microscopy+ electron dispersive X-ray microanalysis (SEM+EDX) (Kiser et al., 2009). Similarly, the $\mathrm{TiO}_{2}$ concentration was about $3.2 \mu \mathrm{g} / \mathrm{L}$ with $305 \mathrm{mg} / \mathrm{kg}$ dry weight in biosolids in an activated sludge plant serving over 200000 people in the UK (Johnson et al., 2011). Westerhoff et al. (2011) also reported effluent titanium concentrations of less than $25 \mu \mathrm{g} / \mathrm{L}$ in 10 representative WWTPs, measured by a combination of filtration, acid digestion, and ICP-OES. Via rotaevaporation, dialysis, and lyophilization as well as high resolution transmission electron microscopy and energy dispersive $\mathrm{X}$-ray analysis, the Ti was found to be present in the size fraction of 4 to $30 \mathrm{~nm}$ in diameter. By using ICP-MS after ammonium persulfate digestion, Khosravi et al. (2012) found total Ti concentrations of 1.6 and $1.8 \mu \mathrm{g} / \mathrm{L}$ in wastewater effluents and $317.4 \mathrm{mg} / \mathrm{kg}$ in sewage sludge from Canada.
Moreover, the $\mathrm{TiO}_{2}$-NPs concentration was found to be $\leq 2.74 \mathrm{~g} / \mathrm{kg}$ in surface sediment from Xiamen Bay, China (Luo et al., 2011). Unfortunately, $\mathrm{TiO}_{2}$-NPs concentrations in soil have not yet been measured, even though a large quantity of $\mathrm{TiO}_{2}$-NPs could ultimately end up in soils, as biosolids are often used as agricultural land amendments (fertilizers).

Note that reported concentrations in aquatic and solid environmental samples are often total Ti concentrations, which have been measured after acid digestion of the sample. These results give us only an upper limit of the real $\mathrm{TiO}_{2}-\mathrm{NP}$ concentrations, as also microparticles of $\mathrm{TiO}_{2}$ could occur and $\mathrm{Ti}$ could also be associated with other particles occurring in the samples. This therefore might reflect the large analytical limitations regarding $\mathrm{TiO}_{2}-\mathrm{NPs}$ in the environment. Therefore, more attention should go to the testing and development of analytical techniques able to measure $\mathrm{TiO}_{2}-\mathrm{NPs}$ in the natural environment.

\section{Potential methods for characterization and measurement of engineered $\mathrm{TiO}_{2}$-NPs}

Previous researchers already reviewed methods to characterize and measure ENPs in the environment (Tiede et al., 2008; Hassellöv et al., 2008; Stone et al., 2010; Silva et al., 2011; Tsao et al., 2011; Weir et al., 2012; Xiao and Wiesner, 2012; Zänker and Schierz,

Table 2 Measured environmental $\mathrm{TiO}_{2}$-NPs in different environmental matrixes and various analytical methods

\begin{tabular}{|c|c|c|c|}
\hline Environmental matrix & Concentration & Measurement method used & Reference \\
\hline Workplace & $\begin{array}{l}11418-45889 \text { particles } / \mathrm{cm}^{3} \text { for } \\
\text { manufacturing workplace; } \\
9512-16337 \text { particles } / \mathrm{cm}^{3} \text { for } \\
\text { European construction industries }\end{array}$ & CPC, SMPS, DC & Duarte et al., 2014 \\
\hline Surface water & $2.1(0.55-6.48) \mu \mathrm{g} / \mathrm{L}$ & Filtration, CFU, ICP-MS & Neal et al., 2011 \\
\hline $\begin{array}{l}\text { Wastewater treatment } \\
\text { plants effluents }\end{array}$ & $\begin{array}{l}<5.0-15.0 \mu \mathrm{g} / \mathrm{L} \\
3.2 \mu \mathrm{g} / \mathrm{L} \\
<25 \mu \mathrm{g} / \mathrm{L} \\
1.6 \& 1.8 \mu \mathrm{g} / \mathrm{L}\end{array}$ & $\begin{array}{l}\text { Filtration, RDL, digestion, } \\
\text { ICP-OES, SEM+EDX }\end{array}$ & $\begin{array}{l}\text { Kiser } \text { et al., 2009; } \\
\text { Johnson } \text { et al., 2011; } \\
\text { Westerhoff } \text { et al., 2011; } \\
\text { Khosravi et al., 2012 }\end{array}$ \\
\hline Biosolids & $\begin{array}{l}1.0-6.0 \mathrm{~g} / \mathrm{kg} \\
305 \mathrm{mg} / \mathrm{kg} \\
317.4 \mathrm{mg} / \mathrm{kg}\end{array}$ & $\begin{array}{l}\text { Filtration, digestion, } \\
\text { ICP-MS, SEM+EDX }\end{array}$ & $\begin{array}{l}\text { Kiser et al., 2009; } \\
\text { Johnson } \text { et al., 2011; } \\
\text { Khosravi et al., } 2012\end{array}$ \\
\hline Sediment & $\leq 2.74 \mathrm{~g} / \mathrm{kg}$ & $\begin{array}{l}\text { Microwave aid acid } \\
\text { digestion, ICP-MS, } \\
\text { SEM+TEM+EDX }\end{array}$ & Luo et al., 2011 \\
\hline
\end{tabular}

CFU: cross flow ultrafiltration; RDL: rota-evaporation, dialysis, and lyophilization 
2012; Gottschalk et al., 2013; Luo et al., 2013; Fabricius et al., 2014). Herein, a short overview is given on methods that may be used to study engineered $\mathrm{TiO}_{2}$-NPs. For a detailed description of these methods, we refer to the specific literature (Tiede et al., 2008; Stone et al., 2010; Zänker and Schierz, 2012; Fabricius et al., 2014). We focus on discussing the advantages and disadvantages of these methods, and possible drawbacks to be taken into account when using these techniques to study engineered $\mathrm{TiO}_{2}$-NPs.

\subsection{Pretreatment and particle fractionation- related techniques}

Sample pretreatment for ENPs analysis, in general, removes coarser components using settling, mild centrifugation, and filtration through filters with relatively large pore size, as well as extraction (Benn et al., 2011; Zänker and Schierz, 2012). These pretreatment techniques are supposed to have only a low impact on the occurrence and morphology of the NPs themselves.

Particle fractionation can help to achieve spatiotemporal separation of the particles, which can be used to obtain fractions of separated NPs that subsequently can be further investigated. Microfiltration and ultrafiltration are the easiest ways to perform such a fractionation task, while field-flow fractionation (FFF) is a more powerful separation method. FFF includes flow field-flow fractionation (FFFF), sedimentation field-flow fractionation, and thermal fieldflow fractionation (Gimbert et al., 2005; Baalousha et al., 2006; Hassellöv et al., 2008; Plathe et al., 2010; Baalousha et al., 2011; von der Kammer et al., 2011). Other important methods are centrifugation and ultracentrifugation (Bootz et al., 2004; Hassellöv et al., 2008), size-exclusion chromatography (SEC) (Weinberg et al., 2011), hydrodynamic chromatography (Tiede et al., 2010), capillary electrophoresis (CE) (Celiz et al., 2011), gel electrophoresis (Surugau and Urban, 2009), isoelectric focusing (Howard, 2010), manipulation between solvent phases such as cloud point extraction (Howard, 2010; Liu et al., 2012), and photophoretic velocimetry (Helmbrecht et al., 2011). Most of these fractionation techniques can be coupled with detectors that can trace the separated particles online.

Some previous studies used microfiltration and ultrafiltration to perform $\mathrm{TiO}_{2}$ particle fractionation, resulting in overestimation of their levels in wastewater treatment plants due to the inclusion of the larger fractions of colloids (Kiser et al., 2009; Johnson et al., 2011; Westerhoff et al., 2011). Ultracentrifugation was previously also used to separate $\mathrm{TiO}_{2}$ particles with a very high inherent size resolution (Kaegi et al., 2008); but this technique seems inadequately represented in environmental NP analysis. Ultracentrifugation is not free of systematic errors (hydrodynamic non-ideality and particleparticle interaction due to differential settling). However, it does not suffer from the artifacts of chromatographic or chromatography-like techniques, such as interactions between the analyte and the stationary phase and shear degradation (SEC), or problems arising from preconcentration, dilution in the channel, particle-membrane interactions, and washing of the particles, which results in re-equilibration because of a change in chemistry (FFF) (Zänker and Schierz, 2012). In spite of having relatively cumbersome and complicated features, FFF is probably the most promising fractionation technique for $\mathrm{TiO}_{2}$-NPs. Similarly, the other separation methods, like manipulation between solvent phases (e.g., cloud point extraction and $\mathrm{CE}$ ), experience problems, such as being very time-consuming, possessing methodological, and handling difficulties, as well as elevated costs (Fabricius et al., 2014). Therefore, an easy to handle, sufficiently available, and moderately expensive tool is needed to separate $\mathrm{TiO}_{2}$-NPs.

\subsection{Techniques for particle detection and characterization}

Many physicochemical properties of ENPs need to be measured to facilitate the understanding their behavior and fate, as well as associated (eco)toxicity. The following methods measure and characterize particles based on their inherent properties (i.e., particle size, size distribution, shape, concentration, surface charge, and surface hydrophobicity).

\subsubsection{Particle detection and characterization}

Particle-size information (hydrodynamic particle diameter) can be obtained through dynamic light scattering (DLS), also known as photon correlation spectroscopy (PCS) (Domingos et al., 2009; Brar and Verma, 2011). DLS is a very powerful tool for studying monomodal particle populations of relatively 
narrow particle-size distributions. However, DLS seems to contradict the size-characterization results according to the more invasive ultracentrifugation technique (Dreissig et al., 2011). Thus, DLS results always need to be scrutinized thoroughly for their accuracy and plausibility tests should be performed.

Static light scattering (SLS) is another lightscattering technique (Wyatt, 1993), which measures the intensity of the scattered light of NPs suspension according to its dependence on the scattering angle. This technique provides information about the particles' molecular weight, radius of gyration of the particles, and particle conformation. As a relatively new method of light scattering, NP-tracking analysis permits the determination of particle-size distribution and, to some extent, particle-number concentration (Gallego-Urrea et al., 2010; Farkas et al., 2011; Zänker and Schierz, 2012). This technique is less prone to masking problems because of its physics. However, it has been widely criticized because too many adjustments and settings have to be chosen by the operator, possibly resulting in too biased results (Farkas et al., 2011; Gallego-Urrea et al., 2011; Zänker and Schierz, 2012). Similarly, information about particle-number concentration and average size can be obtained by laser-induced breakdown detection (LIBD), which is a colloid detection method that uses plasma formation in the focus of a pulsed laser beam (Walther et al., 2004). LIBD is a highly specialized method that was only recently made available through the Cordouan technologies company. Thus, investigators can attempt to use LIBD to measure the $\mathrm{TiO}_{2}-\mathrm{NP}$ contents in solutions since it has already been tried to measure the particle contents in water (Latkoczy et al., 2010).

Additionally, other interesting techniques have been used for various NPs. Fluorescence spectroscopy can provide specific particle-related data such as average particle size for quantum dots (Ju-Nam and Lead, 2008); UV-visible spectrometry can detect the particle size of gold and silver NPs (Stiles et al., 2008; Amendola and Meneghetti, 2009); and O'Connell et al. (2002) used near-infrared fluorescence (NIRF) spectroscopy to collect structural information, such as the chiral wrapping angle, and the diameter distribution of single-walled carbon nanotubes (SWCNTs).

Most particle fractionation methods can be coupled to the aforementioned measurement and char- acterization methods. Here, ultracentrifugation and FFFF provide information about the particle's sphereequivalent hydrodynamic diameter (Stokes diameter); sedimentation FFF can provide the equivalent volumetric diameter; and CE generates the size-to-charge ratio. The limitations of the individual methods can be overcome via the use of a combination of techniques, like FFFF and LIBD (Thang et al., 2000; Baik et al., 2007). The high sensitivity of LIBD counteracts the detection problems often caused by FFFF due to sample dilution, while FFFF eliminates the limits of LIBD in determining particle-size distributions by separating the particles (Zänker and Schierz, 2012). The coupling of FFFF and single-particle ICP-MS is another promising approach (Mitrano et al., 2012).

Coupling may not be limited to one or two detectors. The success of such analyses will always depend to some extent on the type of particles under study and the matrix of the sample. A coupled measurement can include determination of the concentration of the particles, their size distribution, the chemical composition, the crystal structure, the charge (zeta potential), etc. (Lespes and Gigault, 2011).

\subsubsection{NPs visualization}

Microscopy generates the most direct information about size, size distribution, and shape of NPs in water, soils, sediment, and biosolids. Although it is difficult to generate accurate quantitative information from microscopic techniques for large amounts of samples, they can be used to control the quality of results obtained by other techniques. Microscopybased methods include optical approaches (confocal microscopy), as well as electron and scanning probe microscopy. The popular tools for ENP visualization are SEM, TEM, and atomic force microscopy (AFM) (Leppard 2008; Tiede et al., 2008; Zänker and Schierz, 2012). Although microscopy provides relatively accurate estimations of the size and shape of an NP, complicated sample preparation steps (e.g., dehydration, cryofixation, and embedding for SEM) are often required, which can shift samples and create artifacts (e.g., agglomeration). Even in the case of the relatively noninvasive AFM, it is critical to avoid samplepreparation artifacts. Recently, WET-SEM, wet scanning transmission electron microscopy, CryoSEM, in-situ liquid TEM, and other electron 
microscopy techniques have been developed (Bogner et al., 2005; Luo et al., 2007; Grogan et al., 2011; Pietra et al., 2012). Herein, WET-SEM and similar techniques allow the observation of NPs in the liquid phase and reduce sample-preparation artifacts but provide lower resolution (Bogner et al., 2005; Zänker and Schierz, 2012). Additionally, more sophisticated microscopic techniques that provide chemical images and that are only minimally invasive include X-ray spectroscopy with synchrotron radiation (Thieme et al., 2007), laser scanning anti-Stokes Raman scattering (CARS) microscopy (Cheng et al., 2002), and tip-enhanced Raman spectroscopic microscopy (Schmid et al., 2008).

Some cases of microscopy were reported by Zänker and Schierz (2012), who illustrated the differences among these visual methods and their limitations. A general drawback of microscopic techniques is that it is difficult to obtain an accurate estimation of particle size distribution. One can obtain only reliable conclusions on the whole particle population of a sample when a large amount of particles can be counted, which is not often the case. Thus, there is a need for automation and development of suitable image-analysis software, which would enable the characterization of millions of particles (Domingos et al., 2009; Tiede et al., 2009; Zänker and Schierz, 2012).

\subsubsection{Mass spectrometry}

Lots of the detectors described above are not element-specific, which hampers accurate analysis in natural samples containing different types of particles with different compositions. Therefore, hyphenation of size fractionation techniques to sensitive mass spectrometers has previously been introduced. These mass spectrometers are already being used for a long time to measure elemental concentrations in solutions. They consist of an ion source (decomposing the sample and generating ions), a mass analyzer (separating the ions based on mass-to-charge ratio), and a detector system (counting the ions). Some ionization techniques do not completely decompose the compounds present in the sample and can be used for structure identification in liquid and solid biological samples. They include electrospray ionization (ESI) and matrix-assisted laser desorption/ionization
(MALDI). On the other hand, ICP sources completely decompose compounds into individual elements and are used for elemental analysis. Mass analyzers (e.g., ion trap, quadrupole or time-of-flight) cover different mass-to-charge ranges and differ in mass accuracy and achievable resolution. Most of the available analyzers are compatible with electrospray ionization, whereas MALDI is not usually coupled to a quadrupole analyzer. MS techniques have also been used in aerosol characterization, including aerosol time-offlight mass spectrometer (ATOF-MS). An ATOF-MS consists of an aerosol introduction interface; a light-scattering region for sizing and a TOF-MS (time-of-flight mass spectrometer). MS approaches nowadays have been widely applied to measure NPs in the environment (Gray et al., 2012; Liu et al., 2012; Fabricius et al., 2014).

Conventional MS is applicable for identifying unknown compounds and their mass concentrations, as well as their isotopic composition. If size fractionation or selection of the particles based on their size is needed prior to analysis via MS, samples cannot be injected directly into the ion source; therefore, a technique preceding separation technique is needed, such as high performance liquid chromatography. An increasingly popular combination in this respect is FFF-ICP-MS, which allows size separation of the sample with subsequent quantitative and elemental analysis of the obtained size fractions. This development is highly promising for NP analysis, as particles can be simultaneously sized and analyzed in their original environment (Tiede et al., 2008). Moreover, single-particle ICP-MS (SPMS) has recently been introduced as a technique able to analyze metal and metal oxide NPs separately from dissolved ions, without the need for hyphenation to chromatographic techniques for prior size fractionation (Laborda et al., 2011). Therefore, SPMS also has the ability to distinguish particles from truly dissolved species of the same element and to size the single particles.

A comprehensive summary of common and potential methods combining different MSs for separation and detection of engineered $\mathrm{TiO}_{2}$-NPs in the environment is presented in Table 3, although these methods were developed originally to analyze metallic NPs (da Silva et al., 2011). Usually, the very 
Table 3 Common and potential methods for separation and subsequent detection/quantification of $\mathrm{TiO}_{2}$ - $\mathrm{NPs}$ (Tiede et al., 2008; da Silva et al., 2011; Zanker and Schierz, 2012; Fabricius et al., 2014)

\begin{tabular}{cccc}
\hline Separation method & Mechanism & Size range & $\begin{array}{c}\text { Coupled detection/ } \\
\text { quantification technique }\end{array}$ \\
\hline Filtration & Size fractionation & Down to 1 kDa & SEM, ICP-MS, ICP-OES \\
Microfiltration & Size-exclusion membrane & $100 \mathrm{~nm}-1 \mu \mathrm{m}$ & TEM, AFM, ICP-MS \\
Nanofiltration & Size-exclusion membrane & $0.5 \mathrm{~nm}-1 \mathrm{~nm}$ & TEM, ICP-MS \\
CFU & Size-exclusion membrane & $1 \mathrm{~nm}-1 \mu \mathrm{m}$ & TEM, SEM, ICP-MS \\
Dialysis & Size-exclusion membrane & $0.5-100 \mathrm{~nm}$ & TEM, SEM \\
SEC & Packed porous beads as & $0.5-10 \mathrm{~nm}$ & ICP-MS \\
& stationary phase & & \\
Ultracentrifugation (UC) & Acceleration up to $10^{6} g$ & $100 \mathrm{Da}-10 \mathrm{GDa}$ & SEM, TEM, EDS, XRF, \\
& ICP-MS, ICP-OES \\
FFF & $\begin{array}{c}\text { Physical separation in an open } \\
\text { tube based on an applied field }\end{array}$ & $1 \mathrm{~nm}-1 \mu \mathrm{m}$ & ICP-MS, ICP-OES \\
Electrophoretic mobility & Charge-size distribution & $3 \mathrm{~nm}-1 \mu \mathrm{m}$ & ICP-MS, ICP-OES \\
& along a gradient & & \\
\hline
\end{tabular}

first step is to pre-fractionate samples through settling, filtration or centrifugation. Based on the fact that a comprehensive characterization (e.g., size, concentration, and shape) in different matrixes is required, NPs need to be determined via separation using selected methods such as filtration, micro-filtration, nano-filtration, cross-flow ultrafilteration, dialysis, size-exclusion chromatography, FFF, and electrophoretic mobility in conjunction with appropriate coupled techniques (Table 3). Unlike gold NPs, the background of $\mathrm{Ti}$ in nature is much higher. Subsequently, to identify engineered $\mathrm{TiO}_{2}$-NPs completely in the environment, several tracing techniques such as stable isotope and rare element tracing techniques are also considered to be coupled comprehensively in the future (Neal et al., 2011; Larner and Rehkamper, 2012).

\subsubsection{Surface charge and surface hydrophobicity}

Surface charge, expressed as zeta potential, critically influences the interaction of an NP with its environment. Surface charge measurements have been recently reviewed comprehensively by Cho et al. (2013). The zeta potential measurement depends on the strength and valency of ions present in the NP suspension. High ionic strength and high valency ions compress the electric double layer, resulting in reduction of the zeta potential. The $\mathrm{pH}$, i.e., the concentration of hydrogen ions in the medium, greatly influences the zeta potential as well. When the suspension is acidic, NPs acquire more positive charge, and vice versa. Therefore, a zeta potential value without indication of solution $\mathrm{pH}$ is a virtually meaningless number. It is recommended that information on their NPs suspension be precisely described when reporting the zeta potential, including ionic strength, composition of the medium, and the $\mathrm{pH}$. For comparison of results across different studies, it is conceivable to normalize the zeta potential by $\mathrm{pC}$ (the negative logarithm of concentration of counterion species) (Kirby and Hasselbrink, 2004). Generally, particles with zeta potential more positive than $+30 \mathrm{mV}$ or more negative than $-30 \mathrm{mV}$ have colloidal stability maintained by electrostatic repulsion and hydration energy (Yotsumoto and Yoon, 1993). One limitation is that in bimodal samples, the zeta potential value of larger particles dominates the scattering signal of smaller particles, similar to DLS size measurements (Murdock et al., 2008).

Surface hydrophobicity is a key determinant of their fate, the transport and toxicity of engineered nanomaterials. Methods for hydrophobicity fall into three categories, i.e., surface adsorption, affinity coefficient, and contact angle. Xiao and Wiesner (2012) have used these methods to characterize the surface hydrophobicity of carbon- and metal-based NPs. Nevertheless, in real samples the low levels of NPs concentrations and the presence of interfering contaminants render the determination of surface charge and surface hydrophobicity quite difficult. 


\section{Summary and perspectives}

Analytical methods for ENPs are still under development. Until now, these methods have not been able to provide sufficiently reliable data. Moreover, processes to analyze NPs in the environment are most often laborious, expensive, and/or demand specialized and trained operators. Even though some techniques, such as FFF-ICP-MS and single particle ICP-MS, provide powerful tools for the quantification of most metal-based NPs, they also demand welleducated and highly trained operators. An ideal analytical method is needed to allow easy simultaneous determination of all physicochemical properties of an NP by real-time sampling. Although a wide range of techniques is available, the existing techniques do not yet fulfill all desirable criteria and most have considerable limitations when applied in a specific environmental medium. However, before new techniques are being developed, existing techniques have to be combined in such a way that data validation is possible, accompanied by careful sample preparation. Additionally, there is a need for reference materials and standardized protocols to use these combinations of analytical methods for determination of specific NPs in the relevant media.

Although there are already various techniques that work very well, at least in laboratory experiments, it is necessary to develop appropriate strategies using these techniques to determine engineered $\mathrm{TiO}_{2}-\mathrm{NPs}$ in real environments. Considering the current situation of analytical methods and the large production and measured environmental concentrations of $\mathrm{TiO}_{2}-$ NPs around the world and the potential exposure from their applications to humans and the environment, it is still urgently needed to develop appropriate analytical techniques for a reliable determination of these NPs to facilitate their relevant risk assessment.

\section{References}

Amendola, V., Meneghetti, M., 2009. Size evaluation of gold nanoparticles by UV-vis spectroscopy. The Journal of Physical Chemistry C, 113(11):4277-4285. [doi:10.1021/ jp8082425]

Baalousha, M., Kammer, F.V.D., Motelica-Heino, M., et al., 2006. Size-based speciation of natural colloidal particles by flow field flow fractionation, inductively coupled plasma-mass spectroscopy, and transmission electron microscopy/X-ray energy dispersive spectroscopy: colloids-trace element interaction. Environmental Science
\& Technology, 40(7):2156-2162. [doi:10.1021/es05149 $8 \mathrm{~d}]$

Baalousha, M., Stolpe, B., Lead, J.R., 2011. Flow field-flow fractionation for the analysis and characterization of natural colloids and manufactured nanoparticles in environmental systems: a critical review. Journal of Chromatography A, 1218(27):4078-4103. [doi:10.1016/j. chroma.2011.04.063]

Baik, M.H., Yun, J.I., Bouby, M., et al., 2007. Characterization of aquatic groundwater colloids by a laser-induced breakdown detection and ICP-MS combined with an asymmetric flow field-flow fractionation. Korean Journal of Chemical Engineering, 24(5):723-729. [doi:10. 1007/s11814-007-0033-7]

Benn, T.M., Pycke, B.F.G., Herckes, P., et al., 2011. Evaluation of extraction methods for quantification of aqueous fullerenes in urine. Analytical and Bioanalytical Chemistry, 399(4):1631-1639. [doi:10.1007/s00216-0104465-2]

Bogner, A., Thollet, G., Basset, D., et al., 2005. Wet STEM: a new development in environmental SEM for imaging nano-objects included in a liquid phase. Ultramicroscopy, 104(3-4):290-301. [doi:10.1016/j.ultramic.2005.05.005]

Bootz, A., Vogel, V., Schubert, D., et al., 2004. Comparison of scanning electron microscopy, dynamic light scattering and analytical ultracentrifugation for the sizing of poly (butyl cyanoacrylate) nanoparticles. European Journal of Pharmaceutics and Biopharmaceutics, 57(2):369-375. [doi:10.1016/S0939-6411(03)00193-0]

Brar, S.K., Verma, M., 2011. Measurement of nanoparticles by light-scattering techniques. TrAC Trends in Analytical Chemistry, 30(1):4-17. [doi:10.1016/j.trac.2010.08.008]

Carlotti, M.E., Ugazio, E., Sapino, S., et al., 2009. Role of particle coating in controlling skin damage photoinduced by titania nanoparticles. Free Radical Research, 43(3): 312-322. [doi:10.1080/10715760802716633]

Celiz, M.D., Colon, L.A., Watson, D.F., et al., 2011. Study on the effects of humic and fulvic acids on quantum dot nanoparticles using capillary electrophoresis with laserinduced fluorescence detection. Environmental Science \& Technology, 45(7):2917-2924. [doi:10.1021/es1031097]

Chen, C.Y., 2010. Biologcial Effects of Titanium Dioxide Nanomaterials and Its Safe Application. Scientific Press, Beijing, China, p.2-3 (in Chinese).

Cheng, J.X., Jia, Y.K., Zheng, G.F., et al., 2002. Laserscanning coherent anti-stokes Raman scattering microscopy and applications to cell biology. Biophysical Journal, 83(1):502-509. [doi:10.1016/S0006-3495(02)75186-2]

Cho, E.J., Holback, H., Liu, K.C., et al., 2013. Nanoparticle characterization: state of the art, challenges, and emerging technologies. Molecular Pharmaceutics, 10(6):20932110. [doi:10.1021/mp300697h]

da Silva, B.F., Pérez, S., Gardinalli, P., et al., 2011. Analytical chemistry of metallic nanoparticles in natural environments. TrAC Trends in Analytical Chemistry, 30(3):528-540. [doi:10.1016/j.trac.2011.01.008] 
Domingos, R.F., Baalousha, M.A., Ju-Nam, Y., et al., 2009. Characterizing manufactured nanoparticles in the environment: multimethod determination of particle sizes. Environmental Science \& Technology, 43(19):7277-7284. [doi:10.1021/es900249m]

Dreissig, I., Weiss, S., Hennig, C., et al., 2011. Formation of uranium(IV)-silica colloids at near-neutral pH. Geochimica et Cosmochimica Acta, 75(2):352-367. [doi:10. 1016/j.gca.2010.10.011]

Du, W.C., Sun, Y.Y., Ji, R., et al., 2011. $\mathrm{TiO}_{2}$ and $\mathrm{ZnO}$ nanoparticles negatively affect wheat growth and soil enzyme activities in agricultural soil. Journal of Environmental Monitoring, 13(4):822-828. [doi:10.1039/ c0em00611d]

Duarte, K., Justino, C.I.L., Freitas, A.C., et al., 2014. Direct-reading methods for analysis of volatile organic compounds and nanoparticles in workplace air. $\operatorname{Tr} A C$ Trends in Analytical Chemistry, 53:21-32. [doi:10.1016/ j.trac.2013.08.008]

Fabricius, A.L., Duester, L., Meermann, B., et al., 2014. ICPMS-based characterization of inorganic nanoparticlessample preparation and off-line fractionation strategies. Analytical and Bioanalytical Chemistry, 406(2):467-479. [doi:10.1007/s00216-013-7480-2]

Fadeel, B., Garcia-Bennett, A.E., 2010. Better safe than sorry: understanding the toxicological properties of inorganic nanoparticles manufactured for biomedical applications. Advanced Drug Delivery Reviews, 62(3):362-374. [doi:10. 1016/j.addr.2009.11.008]

Farkas, J., Peter, H., Christian, P., et al., 2011. Characterization of the effluent from a nanosilver producing washing machine. Environment International, 37(6):1057-1062. [doi:10.1016/j.envint.2011.03.006]

Farré, M., Gajda-Schrantz, K., Kantiani, L., et al., 2009. Ecotoxicity and analysis of nanomaterials in the aquatic environment. Analytical and Bioanalytical Chemistry, 393(1):81-95. [doi:10.1007/s00216-008-2458-1]

Gallego-Urrea, J.A., Tuoriniemi, J., Pallander, T., et al., 2010. Measurements of nanoparticle number concentrations and size distributions in contrasting aquatic environments using nanoparticle tracking analysis. Environmental Chemistry, 7(1):67-81. [doi:10.1071/EN09114]

Gallego-Urrea, J.A., Tuoriniemi, J., Hassellöv, M., 2011. Applications of particle-tracking analysis to the determination of size distributions and concentrations of nanoparticles in environmental, biological and food samples. TrAC Trends in Analytical Chemistry, 30(3): 473-483. [doi:10.1016/j.trac.2011.01.005]

Gao, Y., Luo, Z.X., He, N.P., et al., 2013. Metallic nanoparticle production and consumption in China between 2000 and 2010 and associative aquatic environmental risk assessment. Journal of Nanoparticle Research, 15(6):1681-1690. [doi:10.1007/s11051-0131681-7]

Gimbert, L.J., Haygarth, P.M., Beckett, R., et al., 2005. Comparison of centrifugation and filtration techniques for the size fractionation of colloidal material in soil suspensions using sedimentation field-flow fractionation. Environmental Science \& Technology, 39(6):1731-1735. [doi:10.1021/es049230u]

Gottschalk, F., Sun, T., Nowack, B., 2013. Environmental concentrations of engineered nanomaterials: review of modeling and analytical studies. Environmental Pollution, 181:287-300. [doi:10.1016/j.envpol.2013.06.003]

Gray, E.P., Bruton, T.A., Higgins, C.P., et al., 2012. Analysis of gold nanoparticle mixtures: a comparison of hydrodynamic chromatography (HDC) and asymmetrical flow field-flow fractionation (AF4) coupled to ICP-MS. Journal of Analytical Atomic Spectrometry, 27(9):15321539. [doi:10.1039/c2ja30069a]

Grogan, J.M., Rotkina, L., Bau, H.H., 2011. In situ liquid-cell electron microscopy of colloid aggregation and growth dynamics. Physical Review E, 83(6):061405. [doi:10. 1103/PhysRevE.83.061405]

Hassellöv, M., Readman, J.W., Ranville, J.F., et al., 2008. Nanoparticle analysis and characterization methodologies in environmental risk assessment of engineered nanoparticles. Ecotoxicology, 17(5):344-361. [doi:10. 1007/s10646-008-0225-x]

Helmbrecht, C., Niessner, R., Haisch, C., 2011. Photophoretic velocimetry-a new way for the in situ determination of particle size distribution and refractive index of hydrocolloids. Analyst, 136(9):1987-1994. [doi:10.1039/ c0an00646g]

Hendren, C.O., Mesnard, X., Droge, J., et al., 2011. Estimating production data for five engineered nanomaterials as a basis for exposure assessment. Environmental Science \& Technology, 45(7):2562-2569. [doi:10.1021/es103300g]

Howard, A.G., 2010. On the challenge of quantifying man-made nanoparticles in the aquatic environment. Journal of Environmental Monitoring, 12(1):135-142. [doi:10.1039/b913681a]

Hussain, S., Vanoirbeek, J.A.J., Luyts, K., et al., 2011. Lung exposure to nanoparticles modulates an asthmatic response in a mouse model. European Respiratory Journal, 37(2):299-309. [doi:10.1183/09031936.00168 509]

Johnson, A.C., Bowes, M.J., Crossley, A., et al., 2011. An assessment of the fate, behaviour and environmental risk associated with sunscreen $\mathrm{TiO}_{2}$ nanoparticles in UK field scenarios. Science of the Total Environment, 409(13): 2503-2510. [doi:10.1016/j.scitotenv.2011.03.040]

Ju-Nam, Y., Lead, J.R., 2008. Manufactured nanoparticles: an overview of their chemistry, interactions and potential environmental implications. Science of the Total Environment, 400(1-3):396-414. [doi:10.1016/j.scitotenv. 2008.06.042]

Kaegi, R., Ulrich, A., Sinnet, B., et al., 2008. Synthetic $\mathrm{TiO}_{2}$ nanoparticle emission from exterior facades into the aquatic environment. Environmental Pollution, 156(2): 233-239. [doi:10.1016/j.envpol.2008.08.004]

Khosravi, K., Hoque, M.E., Dimock, B., et al., 2012. A novel approach for determining total titanium from titanium 
dioxide nanoparticles suspended in water and biosolids by digestion with ammonium persulfate. Analytica Chimica Acta, 713:86-91. [doi:10.1016/j.aca.2011.11. 048]

Kirby, B.J., Hasselbrink, E.F., 2004. Zeta potential of microfluidic substrates: 2. Data for polymers. Electrophoresis, 25(2):203-213. [doi:10.1002/elps.200305755]

Kiser, M.A., Westerhoff, P., Benn, T., et al., 2009. Titanium nanomaterial removal and release from wastewater treatment plants. Environmental Science \& Technology, 43(17):6757-6763. [doi:10.1021/es901102n]

Kiser, M.A., Ladner, D., Hristovski, K.D., et al., 2012. Nanomaterial transformation and association with fresh and freeze-dried wastewater activated sludge: implications for testing protocol and environmental fate. Environmental Science \& Technology, 46(13):7046-7053. [doi:10.1021/es300339x]

Laborda, F., Jimenez-Lamana, J., Bolea, E., et al., 2011. Selective identification, characterization and determination of dissolved silver(I) and silver nanoparticles based on single particle detection by inductively coupled plasma mass spectrometry. Journal of Analytical Atomic Spectrometry, 26(7):1362-1371. [doi:10.1039/c0ja00098a]

Landsiedel, R., Ma-Hock, L., Kroll, A., et al., 2010. Testing metal-oxide nanomaterials for human safety. Advanced Materials, 22(24):2601-2627. [doi:10.1002/adma.2009 02658]

Larner, F., Rehkamper, M., 2012. Evaluation of stable isotope tracing for $\mathrm{ZnO}$ nanomaterials-new constraints from high precision isotope analyses and modeling. Environmental Science \& Technology, 46(7):4149-4158. [doi:10.1021/ es204440d]

Latkoczy, C., Kagi, R., Fierz, M., et al., 2010. Development of a mobile fast-screening laser-induced breakdown detection (LIBD) system for field-based measurements of nanometre sized particles in aqueous solutions. Journal of Environmental Monitoring, 12(7):1422-1429. [doi:10. 1039/c002020f]

Lee, J.H., Kwon, M., Ji, J.H., et al., 2011. Exposure assessment of workplaces manufacturing nanosized $\mathrm{TiO}_{2}$ and silver. Inhalation Toxicology, 23(4):226-236. [doi:10.3109/ 08958378.2011.562567]

Leppard, G.G., 2008. Nanoparticles in the environment as revealed by transmission electron microscopy: detection, characterisation and activities. Current Nanoscience, 4(3) 278-301. [doi:10.2174/157341308785161109]

Lespes, G., Gigault, J., 2011. Hyphenated analytical techniques for multidimensional characterisation of submicron particles: a review. Analytica Chimica Acta, 692(1-2):26-41. [doi:10.1016/j.aca.2011.02.052]

Li, S., Wallis, L.K., Ma, H., et al., 2014a. Phototoxicity of $\mathrm{TiO}_{2}$ nanoparticles to a freshwater benthic amphipod: are benthic systems at risk? The Science of the Total Environment, 466-467:800-808. [doi:10.1016/j.scitotenv. 2013.07.059]

Li, S., Wallis, L.K., Diamond, S.A., et al., 2014b. Species sensitivity and dependence on exposure conditions impacting the phototoxicity of $\mathrm{TiO}_{2}$ nanoparticles to benthic organisms. Environmental Toxicology and Chemistry, 33(7):1563-1569. [doi:10.1002/etc.2583]

Lin, D.H., Ji, J., Long, Z.F., et al., 2012. The influence of dissolved and surface-bound humic acid on the toxicity of $\mathrm{TiO}_{2}$ nanoparticles to Chlorella sp. Water Research, 46(14):4477-4487. [doi:10.1016/j.watres.2012.05.035]

Liu, J.F., Yu, S.J., Yin, Y.G., et al., 2012. Methods for separation, identification, characterization and quantification of silver nanoparticles. TrAC Trends in Analytical Chemistry, 33:95-106. [doi:10.1016/j.trac.2011.10.010]

Lomer, M.C.E., Thompson, R.P.H., Powell, J.J., 2002. Fine and ultrafine particles of the diet: influence on the mucosal immune response and association with Crohn's disease. Proceedings of the Nutrition Society, 61(1): 123-130. [doi:10.1079/PNS2001134]

Luo, H., Scriven, L.E., Francis, L.F., 2007. Cryo-SEM studies of latex/ceramic nanoparticle coating microstructure development. Journal of Colloid and Interface Science, 316(2):500-509. [doi:10.1016/j.jcis.2007.07.047]

Luo, P., Morrison, I., Dudkiewicz, A., et al., 2013. Visualization and characterization of engineered nanoparticles in complex environmental and food matrices using atmospheric scanning electron microscopy. Journal of Microscopy, 250(1):32-41. [doi:10.1111/jmi.12014]

Luo, Z.X., Wang, Z.H., Li, Q.Z., et al., 2011. Spatial distribution, electron microscopy analysis of titanium and its correlation to heavy metals: occurrence and sources of titanium nanomaterials in surface sediments from Xiamen Bay, China. Journal of Environmental Monitoring, 13(4): 1046-1052. [doi:10.1039/c0em00199f]

Ma, X.M., Geiser-Lee, J., Deng, Y., et al., 2010. Interactions between engineered nanoparticles (ENPs) and plants: phytotoxicity, uptake and accumulation. Science of the Total Environment, 408(16):3053-3061. [doi:10.1016/j. scitotenv.2010.03.031]

Macwan, D.P., Dave, P.N., Chaturvedi, S., 2011. A review on nano- $\mathrm{TiO}_{2}$ sol-gel type syntheses and its applications. Journal of Materials Science, 46(11):3669-3686. [doi:10. 1007/s10853-011-5378-y]

Mahshid, S., Askari, M., Ghamsari, M.S., 2007. Synthesis of $\mathrm{TiO}_{2}$ nanoparticles by hydrolysis and peptization of titanium isopropoxide solution. Journal of Materials Processing Technology, 189(1-3):296-300. [doi:10.1016/ j.jmatprotec.2007.01.040]

Marra, J., Voetz, M., Kiesling, H.J., 2010. Monitor for detecting and assessing exposure to airborne nanoparticles. Journal of Nanoparticle Research, 12(1):21-37. [doi:10.1007/s11051-009-9695-x]

Maynard, A.D., Aitken, R.J., Butz, T., et al., 2006. Safe handling of nanotechnology. Nature, 444(7117):267-269. [doi:10.1038/444267a]

Menard, A., Drobne, D., Jemec, A., 2011. Ecotoxicity of nanosized $\mathrm{TiO}_{2}$. Review of in vivo data. Environmental Pollution, 159(3):677-684. [doi:10.1016/j.envpol.2010. 11.027] 
Mitrano, D., Ranville, J., Neubauer, K., et al., 2012. Field-flow-fractionation coupled with ICP-MS for the analysis of engineered nanoparticles in environmental samples. Spectroscopy, 27(9):36-44.

Murdock, R.C., Braydich-Stolle, L., Schrand, A.M., et al., 2008. Characterization of nanomaterial dispersion in solution prior to in vitro exposure using dynamic light scattering technique. Toxicological Sciences, 101(2): 239-253. [doi:10.1093/toxsci/kfm240]

Neal, C., Jarvie, H., Rowland, P., et al., 2011. Titanium in UK rural, agricultural and urban/industrial rivers: geogenic and anthropogenic colloidal/sub-colloidal sources and the significance of within-river retention. Science of the Total Environment, 409(10):1843-1853. [doi:10.1016/j. scitotenv.2010.12.021]

O'Connell, M.J., Bachilo, S.M., Huffman, C.B., et al., 2002. Band gap fluorescence from individual single-walled carbon nanotubes. Science, 297(5581):593-596. [doi:10. 1126/science.1072631]

Piccinno, F., Gottschalk, F., Seeger, S., et al., 2012. Industrial production quantities and uses of ten engineered nanomaterials in Europe and the world. Journal of $\mathrm{Na}$ noparticle Research, 14(9):1109. [doi:10.1007/s11051012-1109-9]

Pietra, F., Rabouw, F.T., Evers, W.H., et al., 2012. Semiconductor nanorod self-assembly at the liquid/air interface studied by in situ GISAXS and ex situ TEM. Nano Letters, 12(11):5515-5523. [doi:10.1021/nl302360u]

Plathe, K.L., von der Kammer, F., Hassellöv, M., et al., 2010. Using FIFFF and aTEM to determine trace metalnanoparticle associations in riverbed sediment. Environmental Chemistry, 7(1):82-93. [doi:10.1071/EN09111]

Robichaud, C.O., Uyar, A.E., Darby, M.R., et al., 2009. Estimates of upper bounds and trends in nano- $\mathrm{TiO}_{2}$ production as a basis for exposure assessment. Environmental Science \& Technology, 43(12):4227-4233. [doi:10.1021/es8032549]

Schmid, K., Riediker, M., 2008. Use of nanoparticles in Swiss industry: a targeted survey. Environmental Science \& Technology, 42(7):2253-2260. [doi:10.1021/es071818o]

Schmid, T., Burkhard, J., Yeo, B.S., et al., 2008. Towards chemical analysis of nanostructures in biofilms I: imaging of biological nanostructures. Analytical and Bioanalytical Chemistry, 391(5):1899-1905. [doi:10.1007/s00216-0082100-2]

Shi, H., Magaye, R., Castranova, V., et al., 2013. Titanium dioxide nanoparticles: a review of current toxicological data. Particle and Fibre Toxicology, 10(1):15. [doi:10. 1186/1743-8977-10-15]

Stiles, P.L., Dieringer, J.A., Shah, N.C., et al., 2008. Surface-enhanced Raman spectroscopy. Annual Review of Analytical Chemistry, 1(1):601-626. [doi:10.1146/ annurev.anchem.1.031207.112814]

Stone, V., Nowack, B., Baun, A., et al., 2010. Nanomaterials for environmental studies: classification, reference material issues, and strategies for physico-chemical characterisation. Science of the Total Environment, 408(7):1745-1754. [doi:10.1016/j.scitotenv.2009.10.035]

Surugau, N., Urban, P.L., 2009. Electrophoretic methods for separation of nanoparticles. Journal of Separation Science, 32(11):1889-1906. [doi:10.1002/jssc.2009000 71]

Thang, N.M., Knopp, R., Geckeis, H., et al., 2000. Detection of nanocolloids with flow-field flow fractionation and laser-induced breakdown detection. Analytical Chemistry, 72(1):1-5. [doi:10.1021/ac991016e]

Thieme, J., McNulty, I., Vogt, S., et al., 2007. X-ray spectromicroscopy - a tool for environmental sciences. Environmental Science \& Technology, 41(20):6885-6889. [doi:10.1021/es0726254]

Tiede, K., Boxall, A.B.A., Tear, S.P., et al., 2008. Detection and characterization of engineered nanoparticles in food and the environment. Food Additives \& Contaminants: Part A, 25(7):795-821. [doi:10.1080/026520308020075 53]

Tiede, K., Hassellöv, M., Breitbarth, E., et al., 2009. Considerations for environmental fate and ecotoxicity testing to support environmental risk assessments for engineered nanoparticles. Journal of Chromatography A, 1216(3):503-509. [doi:10.1016/j.chroma.2008.09.008]

Tiede, K., Boxall, A.B.A., Wang, X.M., et al., 2010. Application of hydrodynamic chromatography-ICP-MS to investigate the fate of silver nanoparticles in activated sludge. Journal of Analytical Atomic Spectrometry, 25(7):1149-1154. [doi:10.1039/b926029c]

Tsao, T.M., Chen, Y.M., Wang, M.K., 2011. Origin, separation and identification of environmental nanoparticles: a review. Journal of Environmental Monitoring, 13(5): 1156-1163. [doi:10.1039/c1em10013k]

van Broekhuizen, P., van Broekhuizen, F., Cornelissen, R., et al., 2011. Use of nanomaterials in the European construction industry and some occupational health aspects thereof. Journal of Nanoparticle Research, 13(2): 447-462. [doi:10.1007/s11051-010-0195-9]

van Broekhuizen, P., van Broekhuizen, F., Cornelissen, R., et al., 2012. Workplace exposure to nanoparticles and the application of provisional nanoreference values in times of uncertain risks. Journal of Nanoparticle Research, 14(4):770. [doi:10.1007/s11051-012-0770-3]

von der Kammer, F., Legros, S., Larsen, E.H., et al., 2011. Separation and characterization of nanoparticles in complex food and environmental samples by field-flow fractionation. TrAC Trends in Analytical Chemistry, 30(3):425-436. [doi:10.1016/j.trac.2010.11.012]

Walther, C., Cho, H.R., Fanghanel, T., 2004. Measuring multimodal size distributions of aquatic colloids at trace concentrations. Applied Physics Letters, 85(26):63296331. [doi:10.1063/1.1842359]

Weinberg, H., Galyean, A., Leopold, M., 2011. Evaluating engineered nanoparticles in natural waters. TrAC Trends in Analytical Chemistry, 30(1):72-83. [doi:10.1016/j.trac. 2010.09.006] 
Weir, A., Westerhoff, P., Fabricius, L., et al., 2012. Titanium dioxide nanoparticles in food and personal care products. Environmental Science \& Technology, 46(4):2242-2250. [doi:10.1021/es204168d]

Westerhoff, P., Song, G.X., Hristovski, K., et al., 2011. Occurrence and removal of titanium at full scale wastewater treatment plants: implications for $\mathrm{TiO}_{2}$ nanomaterials. Journal of Environmental Monitoring, 13(5):1195-1203. [doi:10.1039/c1em10017c]

Windler, L., Lorenz, C., von Goetz, N., et al., 2012. Release of titanium dioxide from textiles during washing. Environmental Science \& Technology, 46(15):8181-8188. [doi:10.1021/es301633b]

Wyatt, P.J., 1993. Light-scattering and the absolute characterization of macromolecules. Analytica Chimica Acta, 272(1):1-40. [doi:10.1016/0003-2670(93)80373-S]

Xiao, Y., Wiesner, M.R., 2012. Characterization of surface hydrophobicity of engineered nanoparticles. Journal of Hazardous Materials, 215-216:146-151. [doi:10.1016/j. jhazmat.2012.02.043]

Yotsumoto, H., Yoon, R.H., 1993. Application of extended DLVO theory: I. Stability of rutile suspensions. Journal of Colloid and Interface Science, 157(2):426-433. [doi:10. 1006/jcis.1993.1205]

Zänker, H., Schierz, A., 2012. Engineered nanoparticles and their identification among natural nanoparticles. Annual Review of Analytical Chemistry, 5(1):107-132. [doi:10. 1146/annurev-anchem-062011-143130]

\section{中文概要：}

\section{本文题目: 环境中工程纳米二氧化钛颗粒的表征与测定}

Measurement and characterization of engineered titanium dioxide nanoparticles in the environment

研究目的: 纳米二氧化钛已是防晒霜、化妆品和光催化剂等的常用成分。纳米二氧化钛的大量应用, 已被 证明具有潜在的环境负面影响与人体健康风险。如何分析环境中工程纳米二氧化钛的理化性质 无疑是认识其潜在风险的关键课题。

研究方法: 从工程纳米颗粒可用的表征与测定方法 (如电镜显微方法、色谱与质谱技术等) 的优缺点出发, 结合稳定同位素与稀有元素示踪技术来探讨环境中工程纳米二氧化钛颗粒的分析方法。

重要结论: 环境中工程纳米二氧化钛的表征与测定方法仍需深入的研究, 其可靠性需要现有各种分析技术 的相互验证、良好的样品预处理技术和参考物质、以及稳定同位素与稀有元素技术示踪的配合。

关键词组: 二氧化钛; 工程纳米颗粒; 环境浓度; 产量; 分析方法 